Arq. Bras. Med. Vet. Zootec., v.65, n.2, p.341-345, 2013

\title{
Espinha bífida aberta em bovino: primeiro relato no estado de Minas Gerais
}

[Open spina bifida in calf: first report in Minas Gerais state, Brazil]

\author{
M.A.C. Nicácio ${ }^{1}$, G.D. Carvalho ${ }^{2 *}$, M.T.L. Serrano ${ }^{1}$, A. Lang $^{1}$, M.L. Santana ${ }^{1}$ \\ ${ }^{1}$ Faculdade de Ciências Biológicas e da Saúde - FACISA/Univiçosa - Viçosa, MG \\ ${ }^{2}$ Instituto Federal Norte de Minas Gerais - IFNMG Campus Salinas - Salinas, MG
}

\begin{abstract}
RESUMO
Relatou-se um caso de espinha bífida aberta em uma bezerra de seis dias de idade que apresentava decúbito lateral permanente, pescoço em posição de opistótono, membros torácicos estendidos, impotência funcional dos membros pélvicos e fístulação na região lombar. Todos os achados clínicos, radiográficos e necroscópicos, descritos neste trabalho, são compatíveis com um quadro de espinha bífida aberta, sendo este o primeiro relato no estado de Minas Gerais.
\end{abstract}

Palavras-chave: alteração congênita, bovino, espinha bífida

\begin{abstract}
A case of open spina bifida is reported in a six day old calf which presented permanent lateral decubitus, opisthotonus neck position, stretched forelimbs, non-functional impairment of the hindlimbs and fistula in the lumbar region. All clinical, radiographic and necropsy finds described in this work are consistent with an open spina bifida case. This is the first case report in Minas Gerais State, Brazil.
\end{abstract}

Keywords: bovine, congenital malformation, spina bifida

\section{INTRODUÇÃO}

Diversas malformações congênitas esporádicas ocorrem no sistema nervoso central (SNC), tais como: hidrocefalia, hidranencefalia, microcefalia, dicefalia, espinha bífida, abiotrofia cerebelar, hipoplasia cerebelar, hipermetria hereditária, atrogripose e hipomielinogênese congênita (Saperstein et al., 1975). Embora malformações congênitas sejam facilmente reconhecidas pelas alterações morfológicas e funcionais que produzem, suas causas não são facilmente detectadas. A maioria dos defeitos congênitos hereditários conhecidos é transmitida por genes recessivos autossômicos, que resultam no nascimento de animais defeituosos, cujos progenitores são normais (Radostits et al., 2002).

Recebido em 1 de outubro de 2011

Aceito em 1 de outubro de 2012

*Autor para correspondência (corresponding author)

E-mail: gabriel.carvalho@ifnmg.edu.br
Múltiplos fatores podem estar relacionados com as causas de espinha bífida, entre eles estão as causas genéticas, cromossômicas e ambientais. A ação de teratógenos, como agentes físicos (radiação), químicos, biológicos (infecções virais e bacterianas) ou causas multifatoriais, levam a falha primária no fechamento do tubo neural ou ruptura deste após seu fechamento, gerando assim malformações congênitas da medula, espinha ou do encéfalo (Maxie e Youssef, 2007).

Nos casos de espinha bífida (EB), há uma falha na fusão dos arcos das vértebras, tipicamente na região lombar. Existem graus variáveis, desde a espinha bífida oculta, na qual o defeito é apenas no arco ósseo, até a espinha bífida aberta, muitas vezes associada à meningocele (protrusão das meninges) ou mielomeningocele (protrusão de elementos neurais além das meninges) (Nussbaum et al., 2003). 
Espinha bífida aberta caracteriza-se pela perda da integridade da camada epidérmica, expondo ao meio externo estruturas do sistema nervoso, como medula espinhal e meninges. Verifica-se a presença de cisto na região dorsal, que pode romper-se durante o parto. A falta de proteção da medula espinhal causada pela espinha bífida aberta resulta em deficiências neurológicas (Kottke e Lehmann, 1994).

Este trabalho relata um caso de espinha bífida aberta em uma bezerra de seis dias de idade, baseado nos achados clínicos, radiográficos e necroscópicos.

\section{CASUÍSTICA}

Uma bezerra "meio sangue" Guzerá, nascida em uma propriedade localizada na zona rural do município de São Miguel do Anta, Minas Gerais, apresentava, ao nascimento, dificuldade locomotora. Entre os pais da bezerra, um touro da raça Guzerá e uma vaca mestiça sem raça definida, não foi observada nenhuma anormalidade. O touro, de oito anos de idade, é pai de 30 bezerros normais, sendo 29 mestiços e um de mesma raça. A vaca, de sete anos de idade, está na quinta cria e já pariu quatro bezerras e um bezerro, todos normais.

Aos seis dias de idade, a bezerra foi encaminhada para atendimento em Hospital Veterinário Escola. Na anamnese clínica, o proprietário relatou que, ao nascer, ela não conseguia se levantar e permanecia sempre em decúbito lateral (Fig. 1), necessitando de apoio no momento da amamentação, que acontecia duas vezes ao dia. Apresentava também movimentos de pedalar com os membros torácicos e forçava o pescoço na tentativa de se levantar quando a mãe se aproximava.

Ao exame clínico observou-se uma fístula na região lombar (Fig. 2). O animal permanecia em decúbito lateral, com o pescoço na posição de opistótono, membros torácicos distendidos, espásticos e frios. Constatou-se impotência funcional de membros pélvicos, diminuição da amplitude dos movimentos em articulações femerotibiopatelares. Foram observados temperatura retal de $37,8^{\circ} \mathrm{C}$, frequência respiratória de 16 movimentos por minuto, frequência cardíaca de 140 batimentos por minuto, tempo de preenchimento capilar menor que 3 segundos, pulso arterial forte, sincronizado ao batimento cardíaco, desidratação aproximada de $6 \%$ e mucosa ocular congesta. Ao exame neurológico observaram-se paraplegia e atrofia da musculatura dos membros torácicos e ausência de sensibilidade dolorosa superficial e profunda.

Ao exame radiográfico simples da coluna vertebral na região lombar, verificou-se uma imagem anormal entre as vértebras T11 e L6. Ao se tentar realizar um exame radiográfico contrastado, pode-se observar uma área de dispersão do contraste pelo canal medular na região citada anteriormente. Observou-se, ainda, a presença de cifose e escoliose (cifoescoliose) da coluna vertebral (Fig. 3). Segundo Harkness e Mccormick (1981) e Dumon (2005), o exame radiográfico é uma importante ferramenta no diagnóstico de anomalias congênitas da coluna vertebral.

Devido ao prognóstico desfavorável do retorno à função sensório-motora dos membros e a dificuldade aparente do animal em respirar e se alimentar, o proprietário optou pela eutanásia. O animal foi encaminhado para o Setor de Patologia do Hospital Veterinário da FACISAUniviçosa, onde foi eutanasiado com administração de acepromazina e tiopental sódico, e procedeu-se à realização da necropsia.

Ao exame necroscópico observou-se, no exame externo, presença de uma fístula de $5 \mathrm{~cm}$ de comprimento, $1,3 \mathrm{~cm}$ de largura e $3 \mathrm{~cm}$ de profundidade na região lombar. Ao exame interno foi observado que o ligamento nucal estava espessado, linfonodos mesentérios aumentados de volume e edemaciados. A fistulação não apresentava comunicação com a cavidade abdominal, sendo restrita ao canal medular e musculatura subjacente. O ligamento plantar longo e tendão do músculo flexor profundo dos dedos e músculos posteriores dos membros pélvicos achavam-se contraídos, e o líquido sinovial das articulações dos membros pélvicos estava espessado. Havia presença de cifose e escoliose (cifoescoliose) da coluna vertebral, os rins apresentavam congestão bilateral e o fígado, congestão moderada, e observou-se presença discreta de líquido nos ventrículos cerebrais, e os vasos cerebrais e cerebelares apresentavam-se levemente congestos. 


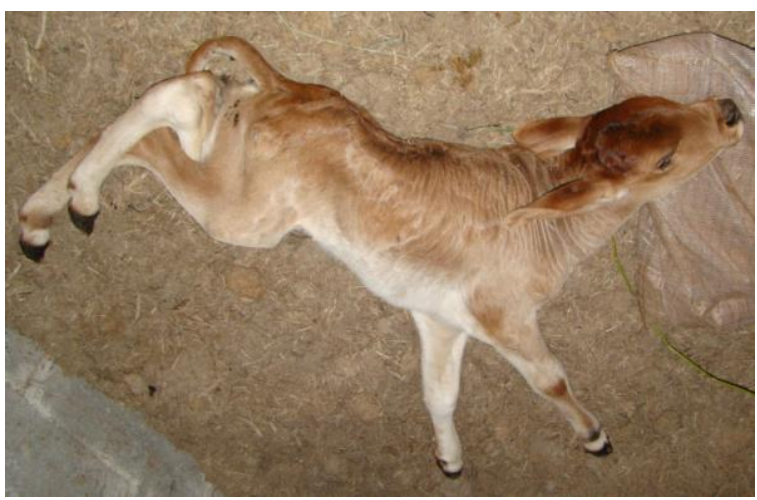

Figura 1. Bezerra em decúbito lateral permanente, apresentando membros torácicos estendidos e pescoço em posição de opistótomo.

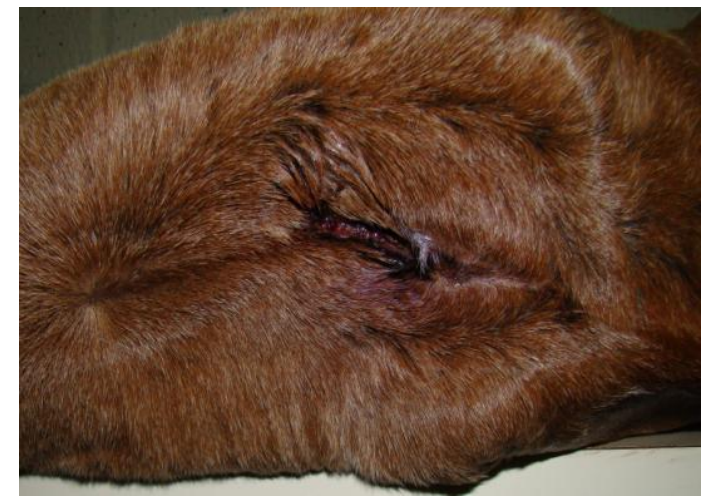

Figura 2. Bezerra com fístula na região lombar.

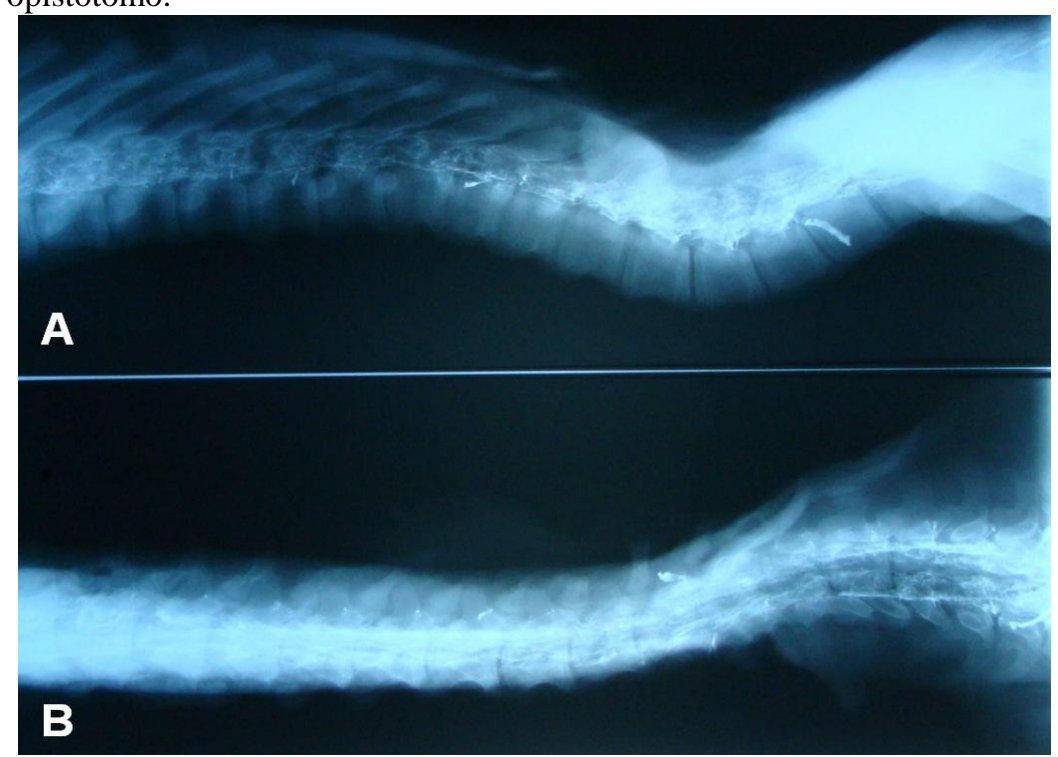

Figura 3. Bezerra. Radiografia da coluna vertebral (porções torácica e lombar). Observa-se cifoescoliose. Projeção látero-lateral (A) e Projeção dorso-ventral (B).

Após a necropsia do animal, a coluna vertebral foi fixada em solução de formol a $10 \%$ e posteriormente dissecada e limpa com solução de peróxido de hidrogênio vol.30 para facilitar a visualização da deformidade da coluna vertebral (Fig. 4, 5 e 6).

\section{DISCUSSÃO E CONCLUSÕES}

Nos casos de espinha bífida aberta, quando associada à meningocele, há protrusão das meninges (Nussbaum et al., 2003). O animal descrito apresentava uma fístula na região lombar, comunicante com o meio externo, restrita ao canal medular, sem conteúdo neuronal exposto, compatível com um quadro de meningocele, cujo cisto provavelmente se rompeu durante o parto. Segundo Chrisman (2005), espinha bífida aberta e meningocele são alterações constantemente associadas à agenesia sacrococcígea (Santos et al., 2005), o que não ocorreu no caso aqui descrito. A meningocele pode ou não estar presente em bovinos. O nível do defeito vertebral geralmente é lombar (Adelmann et al., 1920) ou sacral (McFarland, 1959), embora envolvimento das vértebras torácicas já tenha sido descrito (Goss e Hull, 1939). 


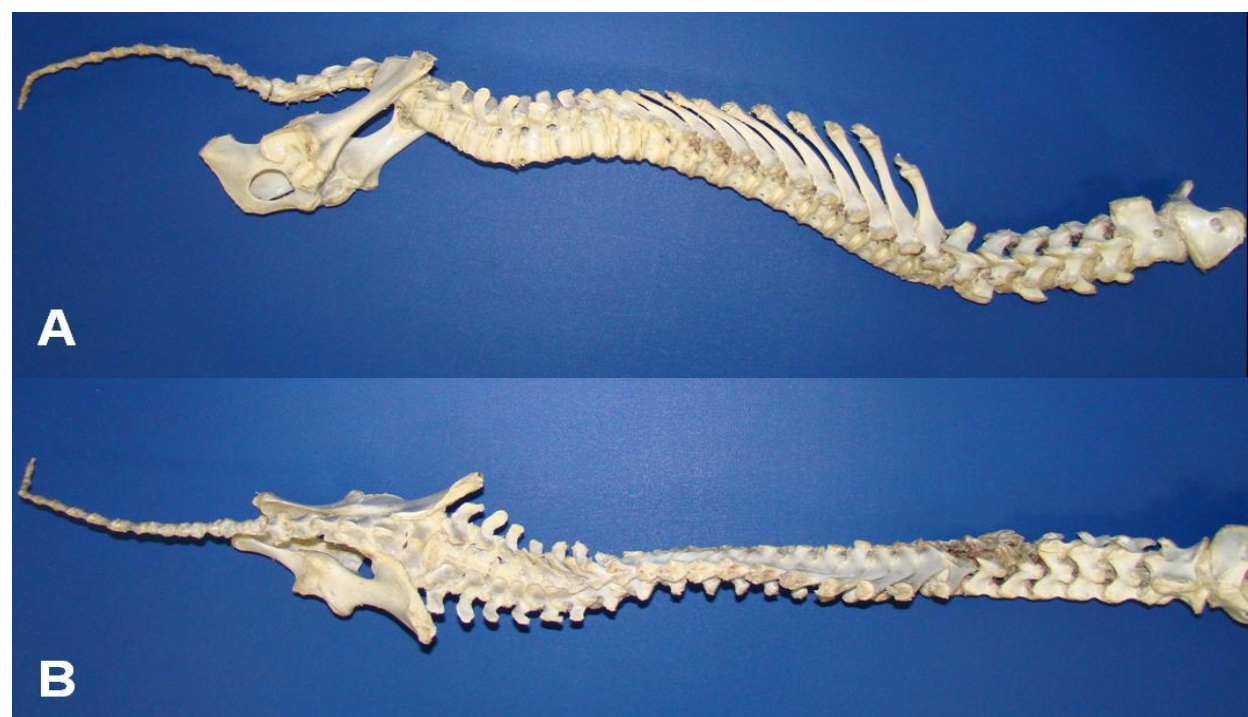

Figura 4. Bezerra. Coluna vertebral dissecada e montada. Observa-se cifoescoliose acentuada. Vista lateral (A). Vista dorsal (B).

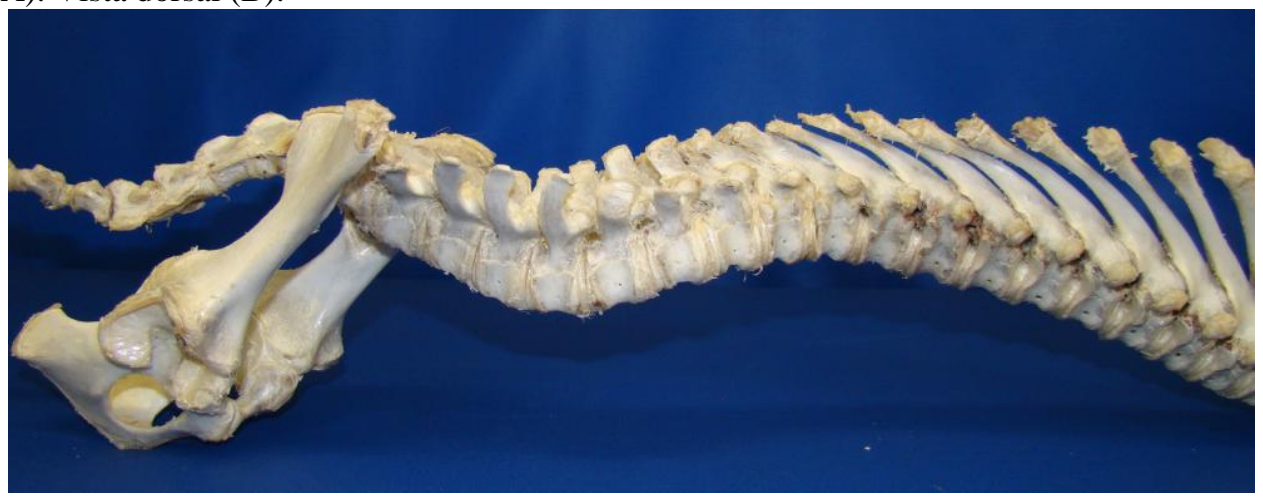

Figura 5. Bezerra. Vista lateral da coluna vertebral, região lombo-torácica.

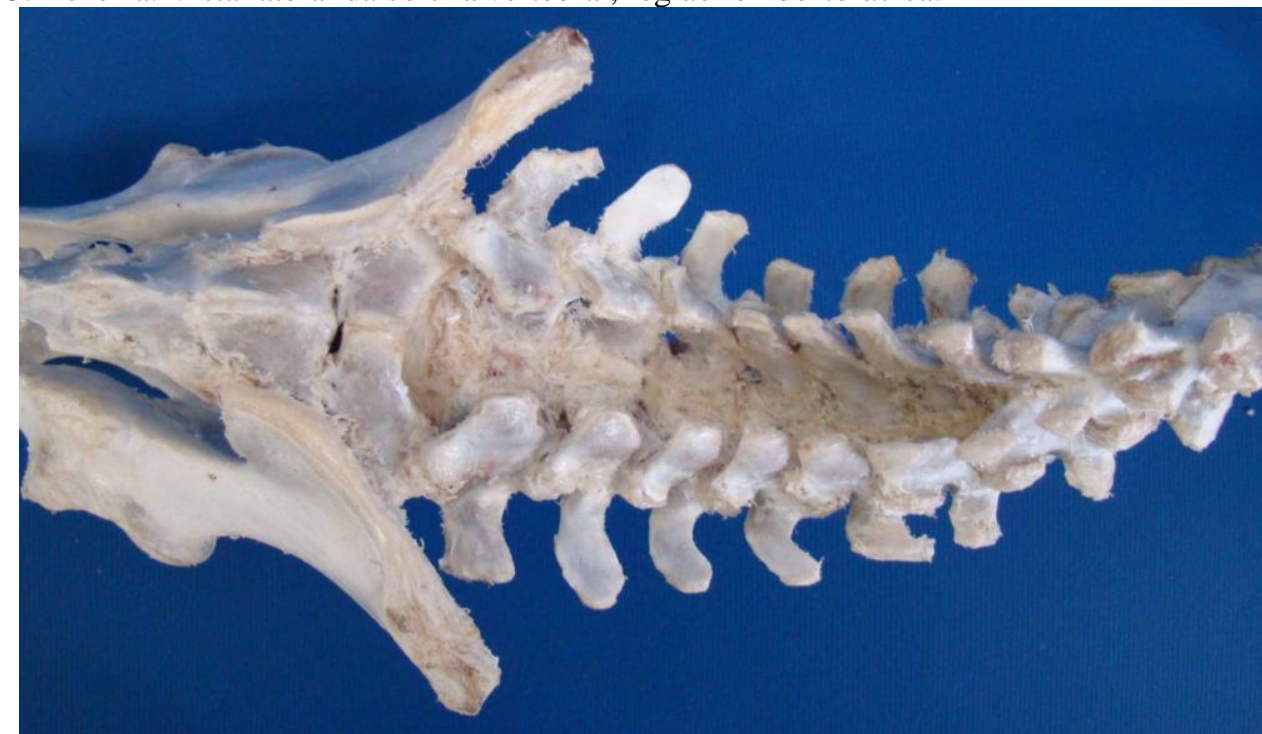

Figura 6. Bezerra. Detalhe da vista dorsal da região lombar da coluna vertebral. Observa-se falha na fusão dos arcos das vértebras lombares, característica de espinha bífida aberta. 
A falta de proteção da medula espinhal causada pela espinha bífida resulta em deficiências neurológicas, com distúrbios sensitivos, motores e ortopédicos, geralmente nos membros pélvicos. As alterações motoras e sensitivas encontradas em casos de espinha bífida aberta variam conforme o nível da lesão e o grau de comprometimento da medula (Cochrane et al., 1996).

As alterações físicas, locomotoras e sensitivas, visivelmente presentes no animal descrito, estavam impedindo-o de se locomover e se manter em posição de estação. Porém, apresentava-se defecando e urinando normalmente. Também foi observada presença discreta de líquido nos ventrículos cerebrais. Segundo Kottke e Lehmann (1994), a falta de controle das funções intestinal e urinária e hidrocefalia estão presentes em $80 \%$ dos casos de mielomeningocele.

Diversos defeitos congênitos já foram descritos em associação com a espinha bífida em bovinos, incluindo a presença de um único rim, aplasia de um corno uterino, atresia ani, cifoescoliose e fenda diafragmática (Goss e Hull, 1939). Neste relato foram observadas alterações associadas à coluna vertebral, como cifoescoliose.

Para o diagnóstico de anomalias congênitas, é fundamental uma boa anamnese clínica, preferencialmente associada ao exame radiográfico (Harkness e McCormick, 1981; Dumon, 2005). Os achados clínicos, radiográficos e necroscópicos relatados neste trabalho são compatíveis com o quadro de espinha bífida aberta. Deve-se ressaltar que os exames clínicos e radiográficos são de grande importância para a suspeita diagnóstica, embora nem sempre sejam conclusivos. Na medicina veterinária, o exame necroscópico é fundamental para confirmação dessa alteração.

\section{AGRADECIMENTOS}

Ao técnico do Laboratório de Anatomia Animal, Hélio Júnior Pires, e ao técnico do Serviço de Patologia do Hospital Veterinário da FACISA/UNIVIÇOSA, Sylvio Miguel.

\section{REFERÊNCIAS}

ADELMANN, H.B. An extreme case of spina bifida with dorsal hernia in a calf. Anat. Rec., v.19, p.29-34, 1920.

CHRISMAN, C. Neurologia para os clínicos de pequenos animais. São Paulo: Roca, 2005. p.315324.

COCHRANE, D.D.; WILSON, R.D.; STEINBOK, $P$. Prenatal spinal evaluation and functional outcome of patients born with myelomeningocele: information for improved prenatal counselling and outcome prediction. Fetal Diagn. Ther., v.11, p.159-168, 1996.

DUMON, C.O sistema músculo-esquelético. In: Neonatologia e pediatria canina e felina. São Caetano do Sul: Inter Book, 2005. p.126-136.

GOSS, L.J.; HULL, F.E. Spina bifida (calf). Cornell Vet., v.29, p.239-240, 1939

HARKNESS, J.E.; MCCORMICK, L.F. Swimming-puppy syndrome in a litter of German Shepherd pups. Vet. Med. Small Anim. Clin., v.76, p.817-821, 1981.

KOTTKE, F.J.; LEHMANN, J.F. Tratado de Medicina Física e Reabilitação de Krusen. 4. ed. São Paulo: Manole, 1994. p.724-725.

MAXIE, M.G.; YOUSSEF, S. The nervous system. In: MAXIE, M.G. (Ed.). Jubb, Kennedy and Palmer's - Pathology of domestic animals. 5.ed. Philadelphia: Elsevier Saunders, 2007. p.281-457.

MCFARLAND, L.Z. Spina bifida with mielomeningocele in a calf. J. Am. Vet. Med. Assoc. v.134, p.32-34, 1959.

NUSSBAUM, R.L.; MCINNES, R.R.; WILLARD, H.F. Genética médica - Thompson \& Thompson. 6. ed. Rio de Janeiro: Guanabara Koogan, 2002. 640p.

RADOSTITS, O.M.; GAY C.C.; BLOOD D.C.; HINCHCLIFF K.W. Clínica Veterinária. 9.ed. Rio de Janeiro: Guanabara Koogan, 2002. 1737p.

SANTOS, M.S.; ADAMI, M.; OLIVEIRA, A.C.G. et al. Diprosopo em bezerro (relato de caso). Rev. Bras. Saúde Prod. Anim., v.6, p.24-30, 2005.

SAPERSTEIN, G.; LEIPOLD, H.W.; DENIS, S.M. Congenital defects of sheep. J. Am. Vet. Med. Ass., v.167, p.314-321, 1975. 